\author{
Marquette University \\ e-Publications@Marquette
}

College of Education Faculty Research and

Publications

Education, College of

1999

\title{
A Community-Based Parenting Program with Low-Income Mothers of Young Children
}

\author{
Bonnie Nicholson \\ Marquette University \\ Viktor Brenner \\ Waukesha County Technical College \\ Robert A. Fox \\ Marquette University, robert.fox@marquette.edu
}

Follow this and additional works at: https://epublications.marquette.edu/edu_fac

Part of the Education Commons

\section{Recommended Citation}

Nicholson, Bonnie; Brenner, Viktor; and Fox, Robert A., "A Community-Based Parenting Program with LowIncome Mothers of Young Children" (1999). College of Education Faculty Research and Publications. 180. https://epublications.marquette.edu/edu_fac/180 


\title{
A M D LEY OF PRACTICE APPROACHES
}

\section{A Community-Based Parenting Program with Low-Income Mothers of Young Children}

\author{
by Bonnie C. Nicholson, Viktor Brenner, \& Robert A. Fox
}

\begin{abstract}
Research has established a significant relationship between certain parental characteristics, such as income or parenting practices, and the development of child behavior problems. This study evaluated the effectlveness of a parenting program for low-income parents of children one to five years old which was offered through community-based family resource centers. Seventy-one mothers completed the program and showed significant decreases in their use of verbal and corporal punishment and significant increases in nurturing behaviors; their children's behavior also improved significantly. Forty-five percent of parents also met Jacobson and Truax's (1991) criteria for clinically significant change. Implications for practtioners working with this challenging population are discussed.
\end{abstract}

BASED ON RECENT NATIONAL STATISTICS (Wang \& Daro, 1998), reports of child abuse and neglect during 1997 included over three million children, representing a $1.7 \%$ increase over the previous year. Very young children remain the highest at-risk group, with $78 \%$ of child abuse related fatalities occurring for children who were less than five years old. One goal of parent education programs is to reduce these alarming statistics by teaching parents skills to better manage children's challenging behaviors. Parenting practices can be positively affected through systematic parent education programs that have also been shown to reduce child behavior problems (Rotto \& Kratochwill, 1994; Sheeber \& Johnson, 1994; Strayhorn \& Weidman, 1991; Webster-Stratton, 1994, 1997). However, much of the research on parenting education has focused on predominately middle-class, European-American families. Less is known about the effectiveness of such programs with different socioeconomic and cultural groups. The goal of this study was to examine the effectiveness of a parenting education program with a diverse group of low-income mothers with young children.

While the incidence of child abuse crosses cultural and socioeconomic lines, specific parental characteristics have been linked to both harsh discipline and increased problem behaviors in young children. Fox, Platz, and Bentley (1995) found that young, single, less-educated lower-income mothers were found to use higher levels of verbal and corporal punishment, practice less-positive nurturing behaviors, and experience higher levels of children's behavior problems than older, married, moreeducated, middle-income mothers. McLeod and Shanahan (1993) reported that low-income mothers spanked their children more often and were less responsive to the needs of their children, hypothesizing that the stress of living in poverty may interfere with a parent's ability to respond supportively to their children's needs. Dodge, Pettit, and Bates (1994) found a relationship between low socioeconomic status, a high degree of harsh discipline, and a lessened display of maternal warmth. Brenner and Fox (1998), using a large, representative sample of over one thousand urban families, reported that parental use of verbal and corporal punishment was the best predictor of behavior problems in young children. Researchers have suggested a relationship between these family characteristics (e.g., income level, parent education) and the early onset of externalizing behavior problems in young children (Deater-Deckard \& Dodge, 1997; Dodge et al., 1994). This may explain why children from families persistently on welfare have significantly higher

Families in Society: The Journal of Contemporary Human Services

Copyright 1999 Families International, Inc. 
levels of antisocial behavior (Takeucki, Williams, \& Adair, 1991) and conduct disorder (Velez, Johnson, \& Cohen, 1989).

One solution to break the cycle of negative parentchild interactions that increases behavior problems in young children is to identify at-risk families early and provide alternatives to the use of harsh punishment. A recent evaluation of a parent education program with a diverse group of parents of young children resulted in significant reductions in parental use of verbal and corporal punishment and significant decreases in child behavior problems (Brenner, Nicholson, \& Fox, 1999). However, these parents were predominantly middle-income. The present study examined the effectiveness of a preventative parenting education program with low-income mothers within community-based family resource centers.

\section{Method}

\section{Subjects}

One hundred forty-three mothers of children, aged one to five years old, participated in a parenting program offered through twelve community agencies in a large, urban Midwest city. Mothers were recruited by community agency staff; participation was voluntary. Mothers' average age was 25.65 years $(\mathrm{SD}=7.9$, range $=16-54$ years). Ninety-one $(64 \%)$ mothers were single, thirty-four $(24 \%)$ were married, ten $(7 \%)$ were divorced, with the remaining participants either separated or widowed. Seventy parents $(49 \%)$ had less than a high school education, twenty-four $(17 \%)$ had completed high school, and fortyseven $(33 \%)$ had some college or technical school experience. Stevens and Cho's (1985) system was used to classify family socioeconomic status (SES) by a systematic ranking of parental occupation. Families participating in the study represented predominately a low-income socioeconomic background: $106(73 \%)$ parents were categorized as low SES; the remaining $27 \%$ of the participants could be categorized as lower-middle to middle SES.

To aid in the facilitation of the parenting program and completion of evaluation instruments, participants with more than one child were asked to choose one child between the ages of one and five years old to focus on during the program; eighty-three boys and sixty girls were chosen. Focus children represented diverse ethnic backgrounds, with $108(76 \%)$ African American, thirteen $(9 \%)$ white, seven $(5 \%)$ Hispanic, six $(4 \%)$ Asian, and the remaining children were classified as "other." Parents reported having an average of two children in the home /SD
$=1.46$, range $=0$ to 8$)$ and having an average of six years' experience as a parent ( $\mathrm{SD}=6.08$, range $=0$ to 27 ).

\section{Parent Education Program}

The parenting curriculum was specifically designed to meet the needs of parents of one- to five-year-old children (Fox \& Fox, 1992). Studies demonstrating the effectiveness of STAR (Stop, Think, Ask, Respond) are available (Brenner et al., 1999; Fox, Anderson, Fox, \& Rodriguez, 1991; Nicholson, Janz, \& Fox, 1998). The STAR parenting program has a preventive, educational philosophy that builds on existing family strengths. The curriculum is divided into four major segments.

The first segment of the program addresses how young children influence their parents' thoughts and feel-

\section{One solution to break the cycle of negative}

\section{parent-child interactions that increases}

\section{behavior problems in young children is to identify at-risk families early and provide alternatives to the use of harsh punishment.}

ings (e.g., "When my child talks back to me, I feel angry and worry that my child is becoming disrespectful"), and how these internal events may lead to parent reactions (e.g., yelling for the talking back). To encourage parents to gradually adopt a more thoughtful parenting style, a simple cognitive strategy is introduced. Using a familiar stop-and-go traffic light with an imbedded STAR acronym, parents are taught to Stop (red light) and Think (yellow light) about their present thoughts and feelings before responding to their children's behaviors. The goal is to gradually slow down the parent's response time in order to allow the parent sufficient time to consider their present thoughts and feelings and how they might alter them (e.g., count to ten, take deep breaths), if necessary, before responding. Parents are given a brightly-colored card displaying the STAR strategy to place somewhere in their home to remind them to use the new strategy with their child. Home practice also is assigned to have parents use this cognitive strategy and report back on its effectiveness during the next class.

The second segment of the curriculum focuses on the parents' expectations of their children. Parents are pre- 
sented with basic information about child development, which is then connected to the STAR cognitive strategy with the addition of the letter " $\mathrm{A}$ " for Ask (yellow light). Parents are taught to ask themselves about the fairness of their expectations while continuing to stop and think

\section{Parents are encouraged to positively} respond to their child's good behavior through the use of rewards and positive attention.

about their own thoughts and feelings. If they find that their expectations are not age-appropriate, parents are encouraged to alter their expectations before they respond to their child. Home practice encourages parents to monitor their developmental expectations. Their success with this added strategy is reviewed in the next class.

The third and fourth segments of the curriculum emphasize how the parent will Respond (green light in the STAR cognitive strategy) to the child. In order to build on existing family strengths, this segment begins by having parents share their own nurturing strategies that encourage their children's development and transmit their family values and culture (e.g., reading, cooking, telling stories, playtime). Existing nurturing skills are then augmented with specific nurturing strategies such as giving good instructions and effective positive reinforcement. Parents are encouraged to positively respond to their child's good behavior through the use of rewards and positive attention. Home practice emphasizes the continued use of the STAR acronym with special attention to nurturing. Finally, the fourth segment specifically addresses discipline. Parents are taught general guidelines and strategies for setting limits on their children's behavior, such as redirection, ignoring, natural consequences, and time-out. Parents learn age-appropriate techniques to help address their child's challenging behavior, such as the use of redirection for younger children and natural consequences for older children. Specific directions are offered to facilitate the use of these skills most effectively within the unique environments of each of the families (e.g., how to use time-out appropriately in a small apartment). Home practice encourages parents to experiment with these new techniques, integrating all of the course segments with the use of the STAR acronym.

The STAR Program was delivered to groups of eight to ten parents in community agencies. This ten-week series of one-hour weekly classes was facilitated in a group format with instruction on specific concepts of the STAR curriculum and discussion on the application of the material to the unique needs of each family. Parents were encouraged to share their successes in practicing these skills at home and to encourage other parents by sharing ideas. Discussion was facilitated through video vignettes demonstrating the STAR concepts in action. To help reinforce class materials, parents received four one-hour audio cassettes and workbooks for in-class exercises and for in-home applications of the parenting concepts. All materials were written at a third-grade reading level, and class content was adapted to meet the unique needs of the parents in the group.

A STAR Leader's Training Program trains community agency staff to deliver the parenting program. Trainees are recruited through community flyers and contact with agency directors. All parent educators are specifically trained in leading the STAR program through a twentyhour training series, including practice teaching exercises to ensure proper delivery of the program. Parent educators receive a STAR Parenting Leader's Guide to aid in the implementation of the program (Fox \& Fox, 1992). All parent educators participating in this study have at least a bachelor's degree and have had significant prior experience working with a diverse group of families. Research has supported the effectiveness of this training program (Fox \& Parroni-Hennick, 1996).

\section{Evaluation Instruments}

The primary measure used to assess the effectiveness of the parenting program was the Parent Behavior Checklist (PBC), (Fox, 1994). The PBC is a hundred-item self-report measure of parenting behaviors for parents of young children aged one to five years old. The PBC measures parenting behaviors on three subscales: (1) discipline measures parental responses to children's challenging behaviors (e.g., "When my child has a temper tantrum, I spank him/ her"), (2) nurturing measures specific positive parent behaviors that promote a child's psychological growth (e.g., "I praise my child for learning new things"), and (3) expectations measures parents' developmental expectations (e.g., "My child should be old enough to share toys"). More effective parenting strategies are associated with lower scores on discipline, higher scores on nurturing, and mid-range scores on expectations. All items are rated using a four-point frequency 
Figure 1. Changes in Parent Behavior Checklist scores following participation in the STAR Parenting Program (means for each subscale are shown).

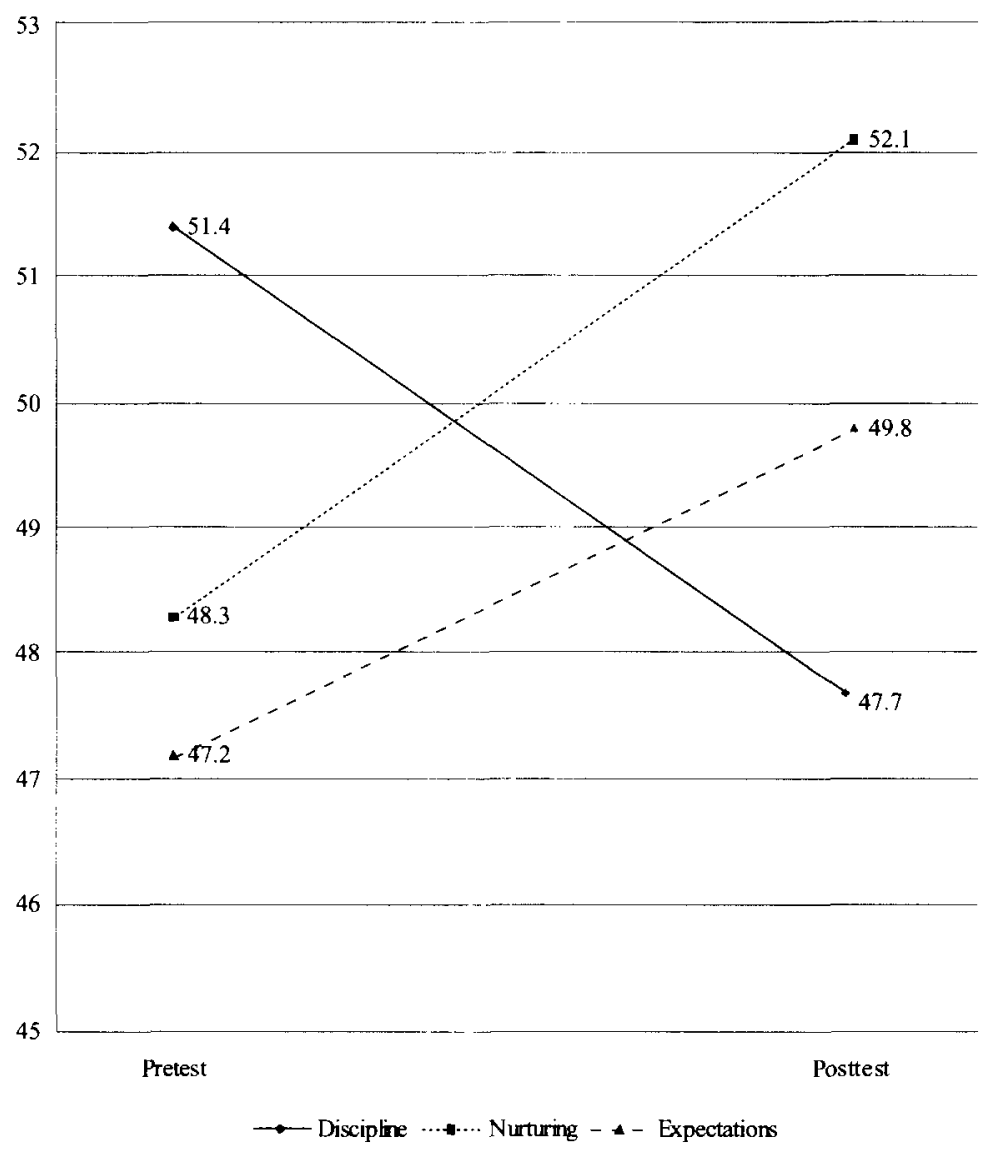

scale and written at a third-grade reading level. A shortened version of the PBC was used in this study (thirtytwo items). Internal consistencies for each subscale on the shortened PBC were acceptable (discipline $=.85$, nurturing $=.73$, and expectations $=.93$ ) and correlated significantly with the longer, original PBC subscales (discipline $=.92$, nurturing $=.91$, and expectations $=.97)$. All scores are converted into uniform $\mathrm{t}$-scores based on a representative sample of 1,056 mothers from a large urban city (Fox, 1992) to allow for comparison across parents of differently-aged children.

The second measure was adapted from the Behavior Screening Questionnaire (BSQ), (Richman \& Graham, 1971), developed to identify emotional and behavioral problems in preschool children. Inter-rater reliabilities for the BSQ have been reported between .77 and .94. For the present study, six behavior items were included (sleeping, not listening, temper tantrums, aggressive, whining, dis- obeying) and rated by parents on a four-point frequency scale. High scores on this scale are indicative of more behavior problems in young children. Parents also completed a series of open-ended questions at the posttest which assessed their satisfaction with the program.

\section{Procedures}

All participants completed the evaluation measures before the parent education program began and immediately following the conclusion of the program. Parent educators were given detailed instructions on the administration of the instruments and were responsible for ensuring their completion. The ten-week parenting program was offered at convenient times for parents being served at one of twelve family resource centers. These family resource centers were located in familiar neighborhood sites that were easily accessible to families with young children. A variety of incentives were used to en- 
courage attendance and completion of the program, including a weekly drawing for prizes such as toys for their children, diapers, or other child care supplies. The agencies were responsible for providing meeting space, child care, and refreshments.

\section{Results}

One hundred forty-three parents of one- to five-yearold children participated in the project; seventy-one $(49.7 \%)$ completed the ten-week program. Initial analyses indicate that mothers who completed the program were significantly older $(\mathrm{F}[1,120]=4.26, \mathrm{p}=.01)$, had

Table 1. Means and standard deviations for the Parent Behavior Checklist and the Behavior Screening Questionnaire at pretest and posttest.

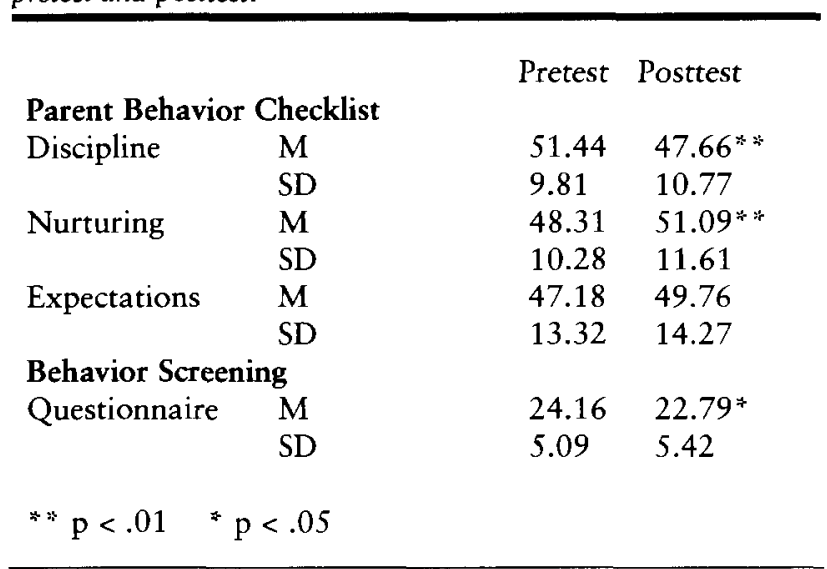

more education $(\mathrm{F}[1,120]=6.70, \mathrm{p}<.05)$, and had higher expectations for their children ( $F[1,120]=9.61, p<$ .01) than those who did not complete the program. To evaluate the effectiveness of the program, repeated measures, multivariate analyses of variance (MANOVAs) were performed to evaluate differences between pretest and posttest (see Figure 1). Parents who completed the program showed statistically significant overall changes on the Parent Behavior Checklist $(\mathrm{l}=0.21$, Exact $\mathrm{F}=6.0$, $\mathrm{p}<.001)$. Univariate follow-up tests indicated that program completers showed statistically significant reductions in discipline $(F[1,70]=11.62, \mathrm{p}<.001)$ and significant increases in nurturing $(\mathrm{F}[1,70]=8.41, \mathrm{p}<.01)$, with changes approaching statistical significance in Expectations $(F[1,70]=3.60, p=.062)$. Table 1 shows the means and standard deviations for pretest and posttest scores on the PBC. Child behavior problems also decreased significantly between pretest and posttest $(\mathrm{F}$
$[1,70]=4.73, p<.05)$. Table 1 shows the means and standard deviations for the pretest and posttest scores on the BSQ. These results indicated that parents completing the program reduced the frequency of verbal and corporal punishment, increased the amount of positive, nurturing behaviors, and reported fewer behavior problems with their young children.

Each parent also was evaluated for clinically significant change (Jacobson \& Truax, 1991) on each PBC scale to determine if changes in their scores were reliable and resulted in posttest scores falling within normal limits. This more stringent measure of program effectiveness allows for an evaluation of the number of families whose pretest to posttest program change represents more positive parenting practices (i.e., less use of verbal and corporal punishment, increase in positive nurturing behaviors, and more reasonable expectations). Seventeen ( $24 \%$ of completers) mothers met these criteria for clinically significant improvement on discipline, nine $(13 \%)$ parents met criteria on nurturing, and nineteen (27\%) parents met the criteria for clinically significant change on expectations. Overall, thirty-two $(\mathbf{4 5 \% )}$ parents who completed the program showed clinically significant improvement on at least one dimension of the PBC.

\section{Discussion}

These results provide preliminary evidence that the STAR program is an effective intervention for lowincome mothers of young children. Mothers who completed the STAR program showed significant decreases in the use of verbal and corporal punishment and increases in nurturing behaviors. Further, using the criterion of clinically significant improvement, $45 \%$ (thirty-two) of mothers who completed the program showed improvement on at least one PBC scale. Despite the stress of poverty, these low-income mothers were able to make positive changes in their parenting behaviors, resulting in a lower occurrence of child behavior problems. On the post-program evaluation, mothers also reported a greater degree of self-confidence in their parenting (e.g., "I know that I am doing the right thing for my child") and a greater understanding of their child's needs (e.g., "I know what my child can do"). Mothers reported that they changed their parenting by stopping and thinking before responding to their children's challenging behavior.

Despite these positive findings, the fact that approximately one-half of the mothers did not complete the program is a cause for concern. Current welfare reform 
forced many of these mothers to abandon the parenting classes in search of employment. Completing the program became less of a priority as other family and personal issues increased in importance. Mothers may have become more concerned with finding employment and maintaining certain benefits than they were with gaining parenting skills. Of particular concern was the fact that

\section{By offering parents the skills to improve their children's behavior, they were} able to see the benefits of positive parenting almost immediately.

younger, less-educated mothers represented the group with the highest drop-out rate. Because these two parental factors tend to be commonly associated with a greater risk for using harsh discipline (Fox, Platz, \& Bentley, 1995), it is these mothers who are most in need of parent education and support. Future research will need to examine ways to better motivate parental involvement in these programs by increasing the importance of positive parenting in the lives of these at-risk families.

\section{Implications for Practitioners}

In light of these findings, specific aspects of this program's delivery should be highlighted. Because of the increased stress of living in poverty, low-income parents need specialized services designed to address their unique needs and motivate their continued participation. Offering these services through community-based family resource centers free of charge, with the addition of child care, transportation services, and refreshments helped to address the needs of these families and increase participation. Maintaining a respectful, nonjudgmental approach and incorporating family and cultural values proved successful in developing good relationships between participants and facilitators. Parent educators frequently deemphasized certain program components (e.g., completing workbook assignments) and allowed parents to use these as resources rather than requirements. Parents appreciated the concrete examples offered by the videotape vignettes and class handouts. Frequent contact between community agency staff, parent educators, and parents also helped to motivate parents' continued in- volvement. By placing a greater emphasis on adapting the program to meet the needs of the parents involved, participants could feel more comfortable with the services provided. By offering parents the skills to improve their children's behavior, they were able to see the benefits of positive parenting almost immediately.

\section{Future Directions}

Given the initial success of the STAR parenting program in improving the parenting practices of low-income mothers, and in light of those parents who did not complete the program, efforts to improve this program are being investigated. We are presently studying the effectiveness of the STAR parenting program delivered individually or to very small groups of parents (maximum four). This innovative individual approach allows parent educators to tailor the program specifically to the unique needs of each family. Parents and facilitators meet oneon-one and discuss specific problems parents are having with their children and apply the STAR concepts in addressing each situation. By allowing the parent educators individual time to meet with and determine each family's unique needs, the STAR parenting program can be adapted to help parents set goals and become more thoughtful and patient with their young children. Preliminary data using this individualized approach with twenty-six families shows promising results including a drop-out rate of only $10 \%$. This individualized format will continue to be investigated in future research to determine its applicability and effectiveness with low-income families.

\section{References}

Brenner, V., \& Fox, R. A. (1998). Parental discipline and behavior problems in young children. Journal of Genetic Psychology, 159(2), 251-256.

Brenner, V., Nicholson, B. C., \& Fox, R. A. (1999). Evaluation of a community-based parent education program with parents of young children. Early Child Development and Care, 148, 1-9.

Deater-Deckard, K., \& Dodge, K. (1997). Externalizing behavior problem and discipline revisited: Nonlinear effects and variation by culture, context, and gender. Psychological Inquiry, 8(3), 161175.

Dodge, K. A., Pettit, G. S., \& Bates, J. E. (1994). Socialization mediators of the relation between socioeconomic status and child conduct problems. Child Development, 65, 649-665.

Fox, R. A. (1994). Parent behavior checklist. Austin, TX: ProEd.

Fox, R. A., Anderson, R. C., Fox, T. A., \& Rodrigueq, M. A. (1991). STAR Parenting: A program for helping parents effectively deal with behavioral difficulties. Young Children, 46, 54-60.

Fox, R. A., \& Fox, T. A. (1992). Leader's guide: STAR parenting pro- 
gram. Bellevue, WA: STAR Parenting, Inc.

Fox, R. A., \& Parroni-Hennick, E. (1996). Evaluating a training program for parental educators. Psychological Reports, 79, 11431150 .

Fox, R. A., Platz, D. L., \& Bentley, K. S. (1995). Maternal factors related to parenting practices, developmental expectations, and perceptions of child behavior problems. The Journal of Genetic Psychology, 156(4), 431-441.

Jacobson, N. S., \& Truax, P. (1991). Clinical significance: A statistical approach to defining meaningful change in psychotherapy research. Journal of Consulting and Clinical Psychology, 59, 12-19.

McLeod, J. D., \& Shanahan, M. J. (1993). Poverty, parenting, and children's mental health. American Sociological Review, 58, 351-366.

Nicholson, B. C., Janz, P. C., \& Fox, R. A. (1998). Evaluating a brief parental-education program for parents of young children. Psychological Reports, 82, 1107-1113.

Richman, M., \& Graham, P. J. (1971). A behavioral screening questionnaire for use with three-year-old children. Journal of Child Psychology and Psychiatry, 12, 5-33.

Rotto, P. C., \& Kratochwill, T. (1994). Behavioral consultation with parents: Using competency-based training to modify child noncompliance. School Psychology Review, 23(4), 669-693.

Sheeber, L. B., \& Johnson, J. H. (1994). Evaluation of a temperamentfocused parent training program. Journal of Clinical Child Psychology, 23, 249-259.

Strayhorn, J., \& Weidman, C. (1991). Follow-up one year after parentchild interaction training: Effects of behavior of preschool children. Journal of the American Academy of Child \& Adolescent Psychiatry, 30(1), 138-143.

Stevens, G., \& Cho, J. H. (1985). Socioeconomic indexes and the new 1980 census occupational classification scheme. Social Science Research, 14, 142-168.

Takeucki, D. T., Williams, D. R., \& Adair, R. K. (1991). Economic stress in the family and children's emotional and behavioral problems. Journal of Marriage and the Family, 53, 1031-1041.

Velez, C. N., Johnson, J., \& Cohen, P. (1989). A longitudinal analysis of selected risk factors for childhood psychopathology. Journal of the American Academy of Child and Adolescent Psychiatry, 28, 861-864.

Wang, C. T., \& Daro, D. (1998). Current trends in child abuse report- ing and fatalities: The results of the 1997 annual fifty-state survey. Chicago: National Committee to Prevent Child Abuse.

Webster-Stratton, C. (1994). Advancing videotape parent training: A comparison study. Journal of Consulting and Clinical Psychology, $62(3), 583-593$.

Webster-Stratton, C. (1997). From parent training to community building. Families in Society, 78(2), 156-171.

Viktor Brenner is assistant professor, Wisconsin School of Professional Pychology, Milwaukee, WI. Bonnie C Nkholson is research assistant and Robert A. Fox is professor, Marquette University, Milwaukee, WI. Correspondence concerning this article should be addressed to Robert $A$. Fox, Marquette University Parenting Center, 749 North 17th. Street, P.O. Box 1881, Mitwaukee,WI 53201-1881. E-mail: 6306foxr@ums.csd.mu.edu.

Authors' note: This research was supported by grants from the Todd Wehr Foundation, Robert T. Foote, and the Child Abuse Prevention Fund.

Original manuscript received: September 28, 1998 Revision received: February 24, 1999

Accepted: March 3, 1999

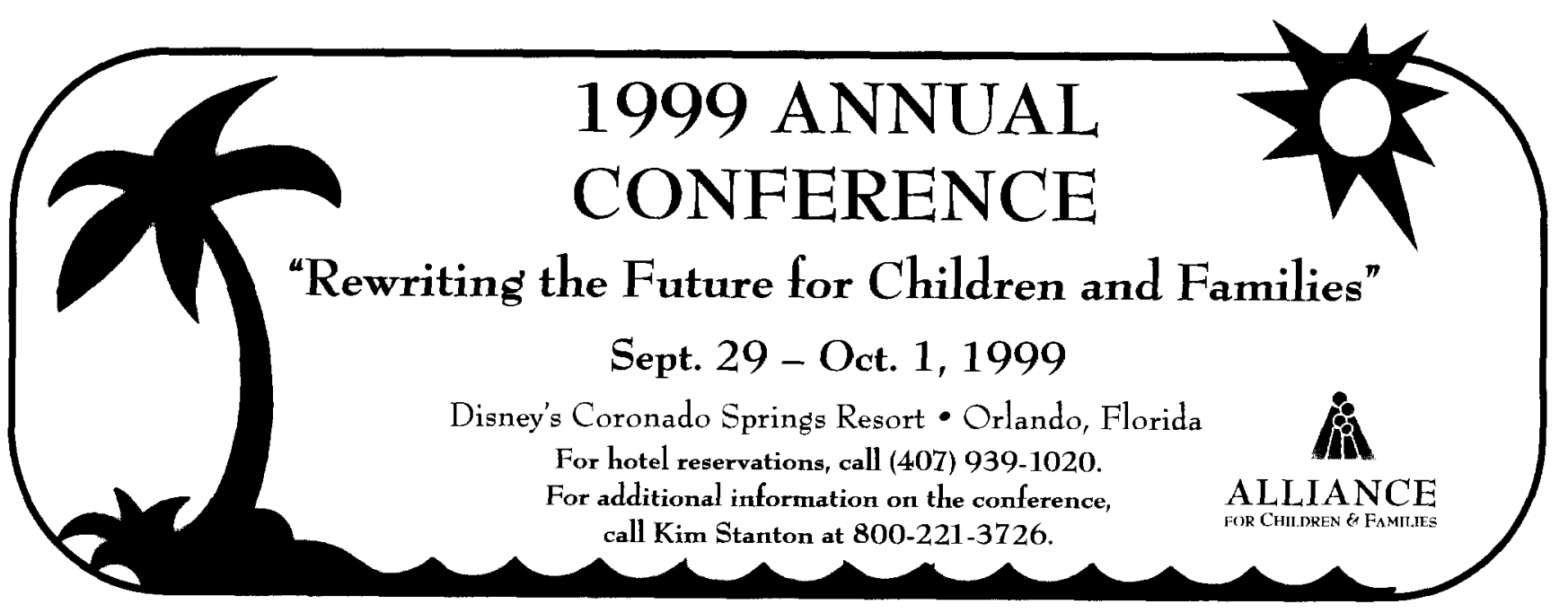

